\title{
Changes in zooplankton diversity and distribution pattern under varying precipitation regimes in a southern temperate estuary
}

\author{
Ana Lígia Primo*, Ulisses Miranda Azeiteiro, Sónia Cotrim Marques, Filipe Martinho, Miguel \\ Ângelo Pardal
}

IMAR - Institute of Marine Research, Department of Zoology, F.C.T., University of Coimbra, 3004-517 Coimbra, Portugal

\section{A R T I C L E I N F O}

\section{Article history:}

Received 17 November 2008

Accepted 19 January 2009

Available online 7 February 2009

\section{Keywords:}

zooplankton community

precipitation regime

diversity

Mondego estuary (Portugal)

\begin{abstract}
A B S T R A C T
The influence of climate variability on the diversity and distribution patterns of zooplankton communities was investigated in the Mondego estuary (Portugal) during four consecutive years characterized by highly variable precipitation and, consequently, river flow regime. Monthly samples were collected along the estuarine gradient at five sampling stations. Seasonal, inter-annual and spatial distributions were evaluated by multivariate analyses and three diversity indices were applied (Species number, Shannon Diversity and Average Taxonomic Distinctness). A two-year drought period presented significant differences in salinity values, especially in 2005 (extreme drought event). During the study period, copepoda was the main dominant group and Acartia tonsa the most abundant species, with the exception of autumn 2006, where high abundances of the cladoceran Penilia avirostris were noticed. Multivariate analysis indicated that zooplankton communities changed from a pre- to a post-drought period indicating the influence of hydrological parameters in communities' structure. The dry period was associated with an increase in zooplankton density, a reduction in seasonality and higher abundance and prevalence of marine species throughout the year. Seasonally, winter/spring communities were distinct from those in summer/autumn. Spatially, salinity-associated differences between upstream and downstream communities were reduced during the drought years, but during the post-drought year, these differences were detected again.
\end{abstract}

(ㄷ) 2009 Elsevier Ltd. All rights reserved.

\section{Introduction}

Under the influence of a variety of inter-related biotic and abiotic structural components and intensive chemical, physical and biological processes, estuaries are highly variable systems. Calbet et al. (2001) and Valdés et al. (2007) have shown how estuarine variability is reflected in the dynamics of the biological populations, particularly planktonic ones. Zooplankton modulates carbon-flow processes through their interactions with higher and lower trophic levels both within the water column and within the benthic community (Isari et al., 2007). Their distribution is affected by both abiotic (David et al., 2005; Marques et al., 2007a, b) and biotic parameters (e.g. predation, competition) (Isari et al., 2007). A range of studies have highlighted how plankton (and particularly zooplankton) might be an important indicator of change in marine systems (e.g. Chiba and Saino, 2003; Molinero et al., 2005) and

\footnotetext{
* Corresponding author.

E-mail address: ana.primo@student.zoo.uc.pt (A.L. Primo).
}

several features point out plankton as particularly good indicators of climate change (e.g. not commercially exploited, short-lived) (Taylor et al., 2002).

In recent years, several studies have focused on the zooplankton communities of the southern arm of the Mondego estuary (e.g. Azeiteiro et al., 1999, 2000; Vieira et al., 2003) and also on the northern arm (e.g. Marques et al., 2006, 2007a, b). Salinity and temperature are the main factors influencing zooplankton distribution, which is thus directly influenced by freshwater inputs (Marques et al., 2006). Hydrological parameters are directly influenced by climatic variations and advection is one of the key mechanism explaining zooplankton distribution and abundance (Kimmerer, 2002). Fluvial contributions are variable because they reflect the seasons as well as the instability of the precipitation regime (Lam-Hoai et al., 2006). Differences in precipitation regimes have been recorded in Portugal with values $45-60 \%$ below average in hydrological year (from October to September) 2004/2005 and normal/regular precipitation values in 2003 and 2006 (http://web. meteo.pt/pt/clima/clima.jsp). Thus, this period provides a good opportunity to investigate zooplankton ecology over a wide range of precipitation. This study attempts to describe the influence of 
rainfall on the distribution of planktonic communities' in a southern European estuary.

\section{Materials and methods}

\subsection{Study area}

The Mondego estuary, located on the Atlantic coast of Portugal $\left(40^{\circ} 08^{\prime} \mathrm{N}, 8^{\circ} 50^{\prime} \mathrm{W}\right)$, consists of two arms, northern and southern, separated by Murraceira Island (Fig. 1). The two arms exhibit different hydrological characteristics: the north arm is deeper (4$8 \mathrm{~m}$ at high tide) has lower residence times ( $<1$ day) and constitutes the main navigation channel, while the south arm is shallower (2-4 m deep, at high tide) has higher residence times (28 days) and is almost silted up in the upper areas, forcing most of the freshwater discharge through the northern arm. In the southern arm, water circulation is mostly due to tides and the freshwater input from a small tributary, the Pranto River. Freshwater discharge of this river is small and artificially regulated by a sluice according to the irrigation needs of the Mondego valley rice fields. Environmental factors in the Mondego estuary provide a large variety of aquatic habitats for populations of marine, brackish and freshwater plankton species (Azeiteiro et al., 1999; Marques et al., 2006), mainly due to salinity and water temperature gradients.

\subsection{Sample collection and analysis}

Zooplankton was collected monthly in the Mondego estuary from January 2003 to December 2006, during high tide, at five stations distributed throughout both arms (Fig. 1). Samples were collected by horizontal subsurface tows (bongo net: mesh size $335 \mu \mathrm{m}$, mouth diameter: $0.5 \mathrm{~m}$ ), equipped with a Hydro-Bios flow meter and preserved in a $4 \%$ buffered formaldehyde seawater solution. Additionally, at each station, water temperature $\left({ }^{\circ} \mathrm{C}\right)$ and salinity were measured. Zooplankton samples were brought to the lab and split into random sub-samples for counting (individuals $\mathrm{m}^{-3}$ ).

Monthly precipitation values were measured at the Soure $13 \mathrm{~F} /$ 01G station and acquired from INAG - Instituto da Água (www. snirh.inag.pt) and freshwater discharge from Mondego River was obtained from INAG station Açude Ponte Coimbra 12G/01AE. Seasonal and inter-annual variability was studied and differences tested using Analysis of Variance (ANOVA) both for zooplankton and environmental parameters.

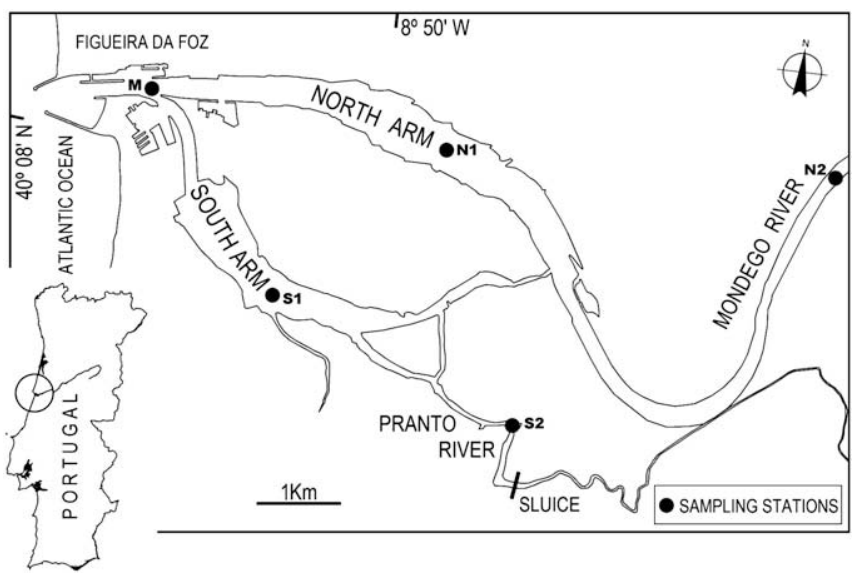

Fig. 1. Map of the Mondego estuary, located on the western coast of Portugal. Sampling stations surveyed in this study are indicated (M, mouth station; S1 and S2, southern arm stations; N1 and N2, northern arm stations).
Spatial and temporal patterns in community structure were examined by multivariate techniques using PRIMER software package (version 5.2.6, PRIMER-E Ltd.) (Clarke and Warwick, 2001). Species abundance data were fourth-root-transformed to balance the contributions from the few very abundant species with the many rare species (Clarke and Warwick, 2001). Bray-Curtis similarity was used to construct a similarity matrix which made-up the basis for a 2-D ordination plot using the non-metric multidimensional scaling (NMDS). Samples were grouped in years, seasons and sampling stations and differences tested by a one-way ANOSIM test (Clarke and Warwick, 2001).

Three biodiversity indices were calculated for each sample: number of species, the Shannon Diversity Index $(\log 2)\left(H^{\prime}\right)$ and the Average Taxonomic Distinctness Index (Delta*). Delta* reflects the taxonomic spread of species among samples and is based in the taxonomic distances between every pair of individuals. This index removes the effect of dominant species and reflects more purely the taxonomic hierarchy. High Delta* values (maximum 100) reflect high taxonomic diversity in the assemblage (Clarke and Warwick, 2001). For each diversity index, differences between seasons were tested using a one-way ANOVA (the Newman-Keuls post-hoc test) or the Kruskal-Wallis ANOVA (the Dunn post-hoc test).

\section{Results}

\subsection{Environmental parameters}

In the Mondego estuary a clear seasonal pattern of rainfall and freshwater discharge was observed during the four-year period, with the highest values observed in winter (Fig. 2A).

Compared to the mean precipitation regime for central Portugal during 1933-2000, the year of 2003 corresponded closely to an average precipitation year except for some above-mean precipitation in October leading to flooding events. As in 2003, 2006 had precipitation values closer to average but in October 2006 another flooding event occurred (Fig. 2A). The years of 2004 and 2005 showed periods with below-mean precipitation (January-May and October-December) causing, in 2005, one of the biggest droughts of the 20th century in Portugal. Freshwater discharge in 2005 was significantly lower than in 2003 and 2006 (Kruskal-Wallis ANOVA: $H=15.287, \mathrm{df}=3, p<0.05)$.

Generally, water temperature and salinity had a similar variation pattern during the sampling period, with lower salinity values and lower temperatures in winter months. However, in 2004 and 2005 salinity values were higher in spring and autumn months, respectively (Fig. 2B). Year 2006 showed the highest annual mean water temperature $\left(16.5 \pm 3.81^{\circ} \mathrm{C}\right)$ but generally, differences in water temperature were not statistically significant between years. Moreover, sampling stations also did not present significant temperature differences between years.

Annual mean salinity in 2005 (28.7), was significantly higher than in 2003 (17.8) or 2006 (16.1) (One-way ANOVA: $F=8.166$, $p<0.001$ ). No significant differences were found for the remaining period. At all sampling stations, salinity presented significantly higher values in 2005 than in 2003 and 2006 (Kruskal-Wallis ANOVA, df $=3, p<0.01$ ).

\subsection{Seasonal and inter-annual zooplankton variability}

Mean monthly zooplankton abundance was highly variable within the study period ranging from 21 (January 2005) to 1102 ind. $\mathrm{m}^{-3}$ (November 2006) (Fig. 3). The highest value was recorded in November 2006, but peaks occurred in different months in the other years. In the year 2003 the maximum value (587 ind. $\mathrm{m}^{-3}$ ) was observed in December, in 2004 it was observed 

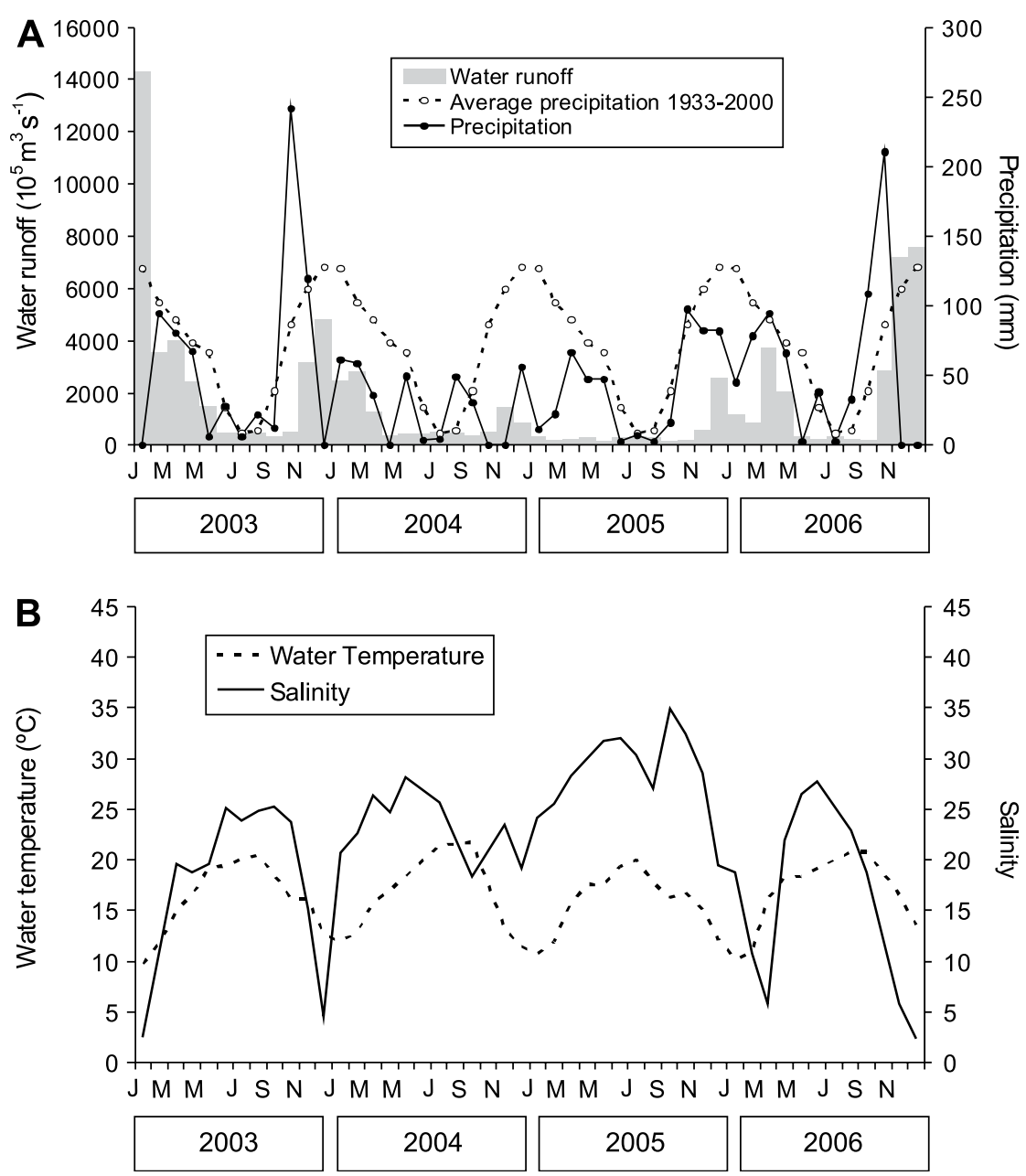

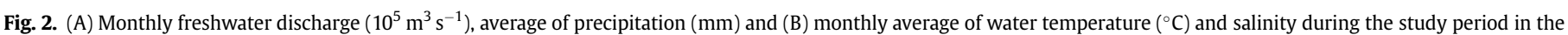
Mondego estuary.

in May (671 ind. $\mathrm{m}^{-3}$ ) and in 2005 in June $\left(682\right.$ ind. $\mathrm{m}^{-3}$ ). However, November seemed to be the month with highest mean total abundance for all the sampling years followed by June which represented another abundance peak (Fig. 3). The year of 2004 showed the highest mean abundance (1378 ind. $\mathrm{m}^{-3}$ ) and 2006 the second highest value (1216 ind. $\mathrm{m}^{-3}$ ).

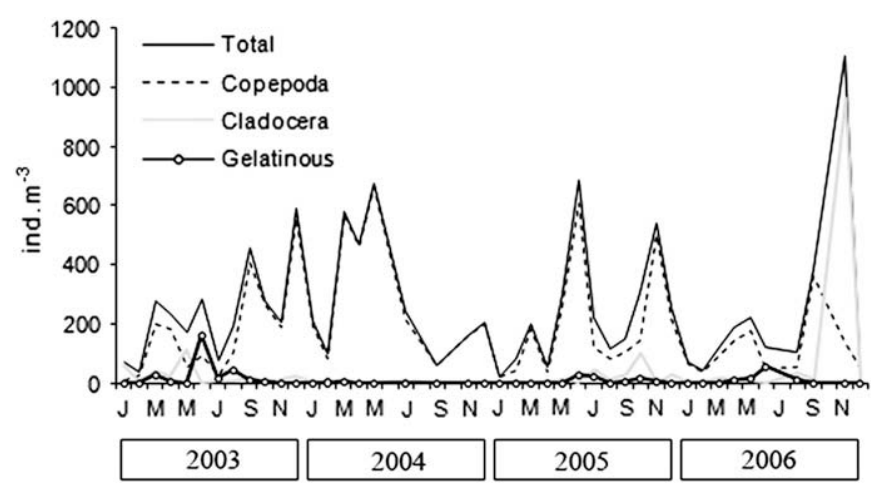

Fig. 3. Mean monthly abundance (ind. $\mathrm{m}^{-3}$ ) values for total zooplankton abundance and three main zooplankton groups (copepoda, cladocera and Gelatinous organisms) during the study period in the Mondego estuary.
A total of 109 species were identified, copepoda being the most abundant zooplankton group (75\% of total abundance), followed by cladocerans (15\%) and gelatinous organisms (Hydrozoa and Thaliacea: $4 \%$ ). Despite the highly variable temporal pattern displayed by zooplankton community as a whole, which tended to mask any clear seasonal sign, this seasonality became more evident when looking at the main zooplankton groups separately (Fig. 3). Copepods had a more variable pattern but seemed to exhibit a peak between March and June and another around November, while gelatinous organisms showed a single peak between March and June. In contrast, cladocerans showed higher mean abundances in the September-November period. Nevertheless, in 2003, a peak was also observed in March and May. The highest cladocera abundance was recorded in autumn 2006.

The species accounting for more than $1 \%$ of the mean total abundance for each period are listed in Table 1. Copepod species assemblage was similar among seasons: Acartia tonsa and Acartia clausi being the most abundant in all seasons. Acartia tonsa showed highest abundances during the winter and $A$. clausi during summer. Diaptomus castor and Acanthocyclops robustus were other copepod species with high abundances during the winter and spring while Temora longicornis had maximum values during the summer and autumn seasons. Daphnia longispina was the most abundant freshwater cladoceran, especially during winter and spring. Podon polyphemoides and Evadne nordmanni abundances increased during 
Table 1

Lists of species mean abundance ( $>1.0 \%$ total abundance) for each season in each year. W, Winter; S, Spring; SM, Summer; and A, Autumn.

\begin{tabular}{|c|c|c|c|c|c|c|c|c|c|c|c|c|c|c|c|c|}
\hline & \multicolumn{4}{|l|}{2003} & \multicolumn{4}{|l|}{2004} & \multicolumn{4}{|l|}{2005} & \multicolumn{4}{|l|}{2006} \\
\hline & W & $\mathrm{S}$ & SM & A & W & $\mathrm{S}$ & SM & A & W & $\mathrm{S}$ & SM & A & W & $\mathrm{S}$ & SM & A \\
\hline \multicolumn{17}{|l|}{ Cladocera } \\
\hline Ceriodaphnia sp. & 0.0 & 0.0 & 0.0 & 0.0 & 15.1 & 6.8 & 0.0 & 0.1 & 0.4 & 0.0 & 0.0 & 0.2 & 30.5 & 24.5 & 0.1 & 27.3 \\
\hline Daphnia longispina & 130.0 & 277.1 & 0.7 & 21.1 & 52.4 & 0.4 & 0.0 & 0.0 & 0.0 & 0.0 & 0.0 & 0.0 & 33.2 & 10.2 & 0.0 & 2.1 \\
\hline Evadne nordmanni & 0.0 & 0.9 & 7.3 & 17.8 & 0.0 & 0.0 & 3.7 & 0.0 & 0.0 & 5.6 & 57.8 & 69.6 & 1.1 & 2.3 & 22.9 & 4.3 \\
\hline Penilia avirostris & 0.0 & 0.0 & 0.0 & 3.6 & 0.0 & 0.0 & 0.0 & 0.0 & 0.0 & 0.0 & 0.0 & 61.7 & 2.1 & 0.4 & 5.3 & 2296.7 \\
\hline Podon leuckarti & 0.0 & 1.3 & 11.5 & 26.4 & 0.0 & 0.0 & 38.5 & 0.7 & 0.0 & 1.2 & 15.8 & 13.4 & 0.1 & 14.4 & 7.3 & 86.3 \\
\hline Podon polyphemoides & 0.0 & 0.5 & 1.6 & 0.2 & 0.0 & 0.0 & 4.3 & 0.0 & 0.0 & 36.0 & 18.9 & 74.5 & 0.1 & 9.0 & 47.4 & 14.9 \\
\hline \multicolumn{17}{|l|}{ Copepoda } \\
\hline Acanthocyclops robustus & 12.7 & 99.0 & 0.7 & 2.0 & 39.0 & 0.9 & 0.0 & 0.2 & 6.7 & 0.0 & 0.0 & 1.8 & 20.5 & 5.4 & 0.1 & 4.6 \\
\hline Acartia clausi & 3.5 & 123.3 & 184.9 & 239.6 & 45.1 & 16.2 & 175.8 & 188.9 & 70.4 & 82.6 & 156.8 & 148.7 & 3.0 & 161.6 & 160.2 & 167.3 \\
\hline Acartia tonsa & 47.2 & 282.8 & 76.2 & 1030.9 & 1088.3 & 2450.3 & 503.5 & 272.8 & 265.5 & 683.7 & 1111.1 & 882.5 & 201.0 & 229.2 & 23.5 & 821.2 \\
\hline Clausocalanus arcuicornis & 0.5 & 5.4 & 7.9 & 5.7 & 3.8 & 1.3 & 10.3 & 0.1 & 3.0 & 3.1 & 6.7 & 16.5 & 1.7 & 2.4 & 6.3 & 100.2 \\
\hline Diaptomus castor & 21.6 & 124.4 & 3.3 & 109.9 & 79.7 & 49.1 & 0.0 & 0.03 & 13.8 & 0.4 & 0.0 & 0.2 & 305.6 & 249.3 & 0.2 & 95.1 \\
\hline Oithona plumifera & 0.4 & 0.5 & 2.6 & 2.9 & 3.0 & 2.8 & 5.2 & 0.4 & 2.0 & 0.6 & 27.1 & 9.5 & 0.9 & 5.3 & 47.5 & 1.8 \\
\hline Paracalanus parvus & 0.6 & 12.1 & 2.3 & 3.4 & 27.4 & 17.9 & 3.8 & 0.4 & 0.2 & 1.3 & 2.9 & 1.2 & 1.3 & 45.7 & 5.3 & 5.1 \\
\hline Temora longicornis & 0.1 & 9.8 & 56.0 & 30.4 & 81.1 & 81.3 & 355.0 & 1.8 & 7.0 & 13.0 & 45.5 & 179.9 & 3.4 & 66.4 & 19.6 & 12.5 \\
\hline \multicolumn{17}{|l|}{ Siphonophora } \\
\hline Diphyes sp. & 0.0 & 0.0 & 0.0 & 0.0 & 0.0 & 0.0 & 0.0 & 0.0 & 0.0 & 0.04 & 34.7 & 5.3 & 0.2 & 33.3 & 108.1 & 3.8 \\
\hline Muggiaea atlantica & 0.0 & 15.1 & 294.0 & 19.0 & 3.7 & 12.4 & 2.9 & 0.1 & 0.1 & 0.2 & 31.6 & 8.9 & 0.8 & 19.8 & 39.6 & 0.9 \\
\hline
\end{tabular}

summer and autumn, mainly in 2005 and 2006. Among cladoceran species, highest abundance was registered for the marine species Penilia avirostris in the autumn of 2006. This species, almost inexistent during the rest of the year, increased its abundance during autumn; in 2006 this increase rose to a seasonal mean of 2297 ind. $\mathrm{m}^{-3}$, representing $62 \%$ of total species abundance for the season. Among gelatinous organisms, the siphonophores Muggiaea atlantica and Diphyes sp. were the most abundant, mainly during spring and summer periods.

\subsection{Diversity measures}

Diversity indices varied distinctly along the estuary during the four years (Fig. 4). Summer samples tended to present higher species number, Average Taxonomic Distinctness and Shannon Diversity. On the other hand, 2004 samples showed, generally, lower diversity.

Spatially, downstream stations M, S1 and N1 presented Delta* values significantly lower in 2004 than in 2005 (One way ANOVA, $\left.F_{\mathrm{M}}=3.142, F_{\mathrm{S} 1}=3.092, F_{\mathrm{N} 1}=3.101, p<0.05\right)$. Also, in station $\mathrm{N} 1$, 2004 had significantly lower Delta* values than in 2003. S and $H^{\prime}$ showed no significantly differences. Upstream station N2 presented no significantly differences between years for any of the indices. Station S2 demonstrated higher numbers of species in 2005 than in 2003 and 2004 (Kruskal-Wallis ANOVA, $H=13.357, \mathrm{df}=3$, $p<0.01$ ) while the Shannon Diversity in 2004 was lower than in subsequent years (Kruskal-Wallis ANOVA, $H=10.057, \mathrm{df}=3$, $p<0.05)$.

\subsection{Community variability}

In general, and particularly if winter values are excluded, zooplankton community was seasonally separated in the MDS ordination plot, particularly years 2003 and 2004 from years 2005 and 2006 (Fig. 5). ANOSIM analysis revealed that 2003 tend to be separated from 2005 and 2006 (ANOSIM test $R=0.694$ and $R=0.722, p=0.001$ ). Also, 2004 and 2006 showed differences (ANOSIM test $R=0.704, p=0.002$ ). Seasonally, winter and spring samples were different from summer and autumn.

Spatial differences can be seen both in MDS ordination (Fig. 6) and in ANOSIM analysis results. Stations M, S1 and N1 formed a relatively tight cluster ( $>50 \%$ similarity) generally separated from
S2 and N2 stations. Notice that 2005 and 2006 samples from S2 stations were included in the downstream stations cluster, as well as 2005 samples from N2 (Fig. 5). Across station groups analysis revealed that stations $M$ and S1 are different from S2 (ANOSIM test $R=0.605$ and $R=0.550, p=0.001$ ).

\section{Discussion}

The drought period of 2004/2005 was the most severe recorded in Portugal during the recent decades (http://web.meteo.pt/pt/ clima/clima.jsp) affecting annual freshwater input into the ecosystem. This allowed the comparison of population fluctuations during the pre- and post-drought period. The drought period was characterized by low freshwater inflow and higher salinities, mainly in 2005. Pre- and post-drought periods differed especially in inflow since in 2006 water reservoirs were at the minimum of their capacity and, as consequence, discharges were small.

\subsection{Influence of climate variability in zooplankton community}

In the Mondego, as in other areas, copepods constitute the most important component of mesozooplankton. Acartia tonsa was the most abundant taxon in the estuary, dominating the majority of the samples and always a significant component of the community, as found by Azeiteiro et al. (1999) and Marques et al. (2006). According to Ianora (1998), this species find a winter benefit from the early phytoplankton bloom in terms of reproductive performance, since its annual peak in egg production rate occurs in February, increasing numbers of juveniles and adults in spring. It hatches from resting eggs in the sediments when temperatures exceed $15^{\circ} \mathrm{C}$ and due to its sensitivity to temperature one might predict an increased period of dominance of $A$. tonsa in response to warmer winters or earlier springs (Sullivan et al., 2007).

Multivariate analyses found winter and spring communities to be distinct from those of summer/autumn, and are characterized by a higher presence of freshwater species, including Diaptomus castor, Acanthocyclops robustus, and Daphnia longispina. Their abundance was higher in pre- and post-drought periods since during higher river flow organisms are advected from upstream to the estuary by the freshwater flux (Marques et al., 2006).

Inter-annually, the drought year of 2005 was distinguished from pre-drought period (2003). In 2003 precipitation values closer to 

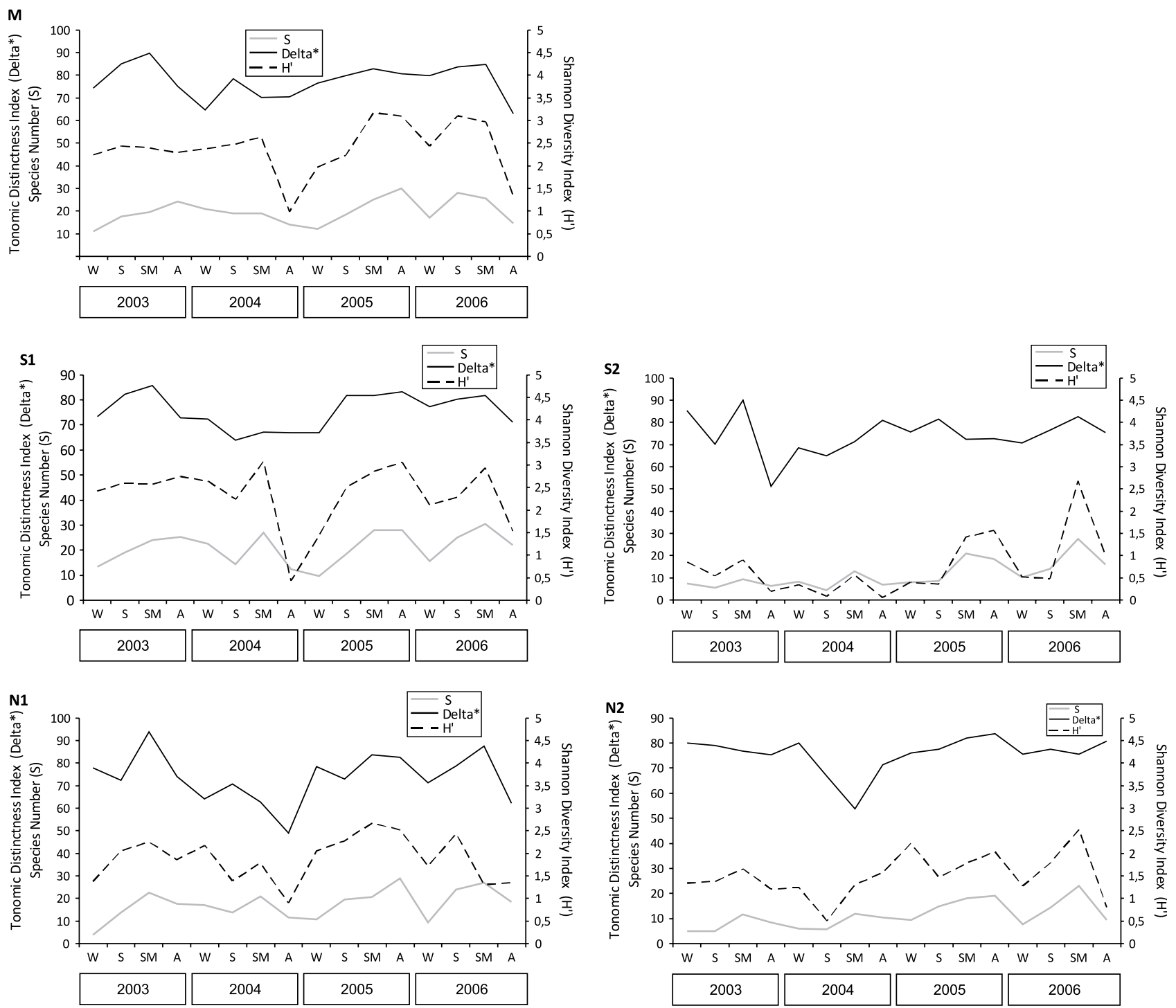

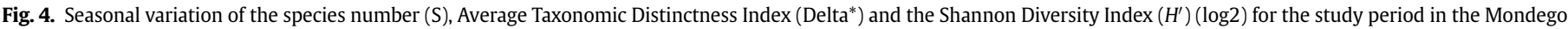
estuary. W, winter; S, spring; SM, summer; and A, autumn.

average allowed the constitution of a community marked by the presence of freshwater species of copepods and cladocerans during winter and autumn. This abundance of freshwater cladocerans has also been observed in other estuaries with significant freshwater influence (Tackx et al., 2004). In summer, copepods were dominated by Acartia clausi and Acartia tonsa, and gelatinous organisms are present in higher abundances.

During the dry years of 2004 and 2005 the community changed. Copepod dominance increased, as a consequence of higher abundances of Acartia tonsa and Acartia clausi. Adult Acartia congeners have distinct seasonal and spatial distribution patterns but nauplii of all species survive well at higher salinities (Chinnery and Williams, 2004). During drought periods seasonality became less obvious. Copepod species including Temora longicornis and Paracalanus parvus increased in abundance, as did the marine cladocerans Podon polyphemoides, Podon leuckarti and Evadne nordmanni. Additionally, the presence of gelatinous organisms was reduced but became more constant throughout the year. This higher abundance and prevalence of marine species through the year were a result of the higher salinities observed during this period as a consequence of reduced river flow.
The pre- and post-drought periods also presented differences. The post-drought period (2006) community was characterized by a higher abundance of copepods, including Diaptomus castor, Acartia tonsa and Acartia clausi, mainly in the winter and spring. On the other hand, in spring and winter of 2003 the cladoceran Daphnia longispina was more abundant than in 2006. The pre- and post-drought periods also differed in their summer community mainly in Siphonophora species. In autumn 2006, the samples were dominated by marine cladocerans, principally Penilia avirostris. This species was an important component of the zooplankton community of many tropical, subtropical and temperate waters (Rose et al., 2004), although recently it has spread to higher latitudes (e.g. the North Sea, Johns et al., 2005). In temperate regions, this species occurs seasonally and are most abundant in summer (Calbet et al., 2001). These organisms constitute a major component of the zooplankton during the periods of high abundance (e.g. Calbet et al., 2001; Ramfos et al., 2006; Mercado et al., 2007). Peaks of high abundance are reached by their ability of change from gamogenic to parthenogenetic reproduction (Atienza et al., 2007). It seems that this temporal occurrence is mainly related to the availability of their adequate food. Penilia avirostris ingests a wide spectrum of 


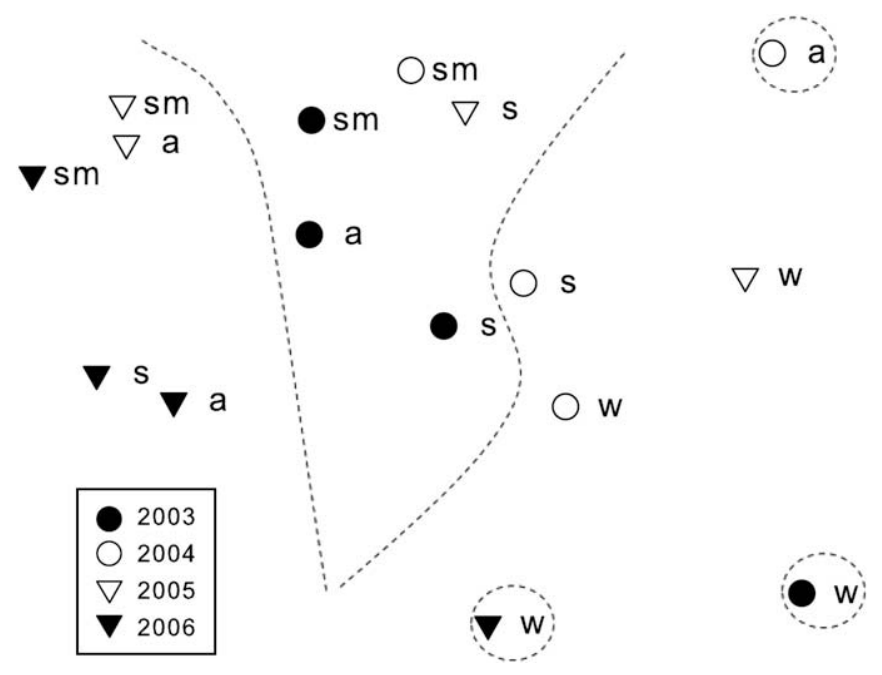

Fig. 5. Two-dimensional non-metric MDS ordination plot of zooplankton abundance during the sampling period. MDS plots were based on triangular matrices of BrayCurtis similarities using fourth-root-transformed species abundance data. w, winter; s, spring; sm, summer; and a, autumn. Stress 0.15. Dashed lines group samples with more than $60 \%$ similarity.

microbial organisms, from flagellates $<2 \mu \mathrm{m}$ to chain-forming diatoms, showing a clear advantage over copepods (Katechakis et al., 2004).

Any effects of the drought period on species spatial distributions are not so clear. Differences were mainly detected in the south arm between downstream (M, S1) and upstream sampling station S2. Downstream, marine zooplankton species tend to become more important because of the higher influence of saline waters while at the upstream stations freshwater influence from the Mondego and the Pranto rivers is predominant. In 2003/2004, communities presented salinity-related differences between upstream (N2, S2) and downstream (M, N1, S1) stations, however, in 2005 (during the drought), this did not happen. During the dry year 2005, river flow was at a minimum allowing a more pronounced intrusion of saline waters and decreasing salinity differences between upstream and downstream stations. In the post-drought period this distinction

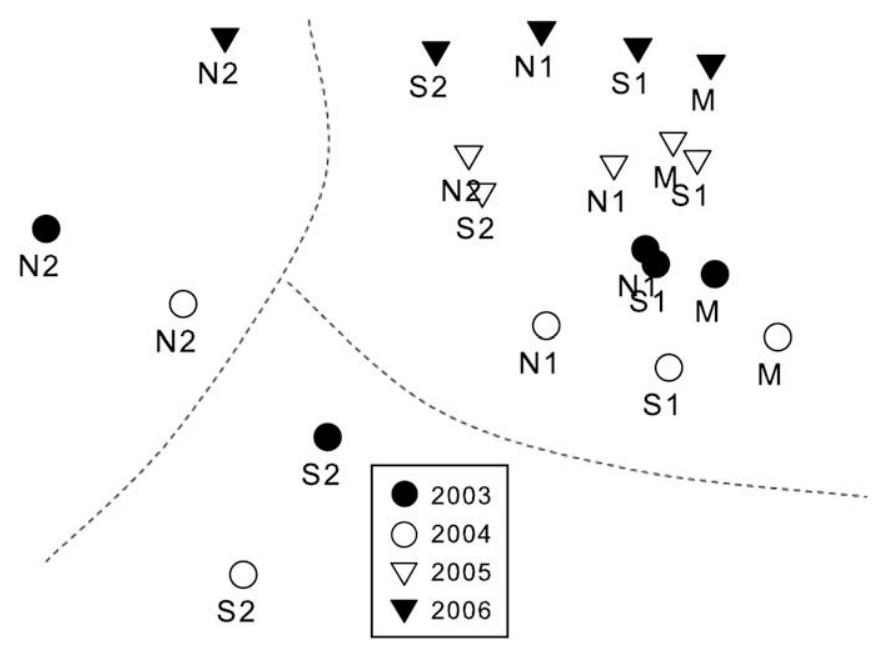

Fig. 6. Two-dimensional non-metric MDS ordination plot of zooplankton abundance during the sampling period in each sampling station. MDS plots were based on triangular matrices of Bray-Curtis similarities using fourth-root-transformed species mean annual abundance data (M, mouth station; S1 and S2, southern arm stations; N1 and N2, northern arm stations). Stress 0.11. Dashed lines group samples with more than $50 \%$ similarity. was again detected in the north arm upstream community sampled at station N2. The lower residence and stronger daily changes in salinity at this station can explain this faster recovery.

\subsection{Influence of climate variability in diversity}

As a consequence of community variability, diversity indices also differed. Seasonally, summer samples presented higher diversity. The low freshwater flow from the Mondego River during these periods allowed a major penetration of seawater and a replacement of the freshwater community by marine species in the most upstream sections of the estuary resulting in higher zooplankton diversity. In almost all estuaries, the greatest species diversity occurs near the mouth (lower reach) since that diversity is enhanced through exchanges between the opportunistic estuarine communities and coastal zooplankton, characterized by the presence of large consumers (chaetognaths, copepods, veligers) (LamHoai et al., 2006). The dry year 2004 showed lower diversity and Average Taxonomic Distinctness mainly in downstream stations. This lower diversity was probably due to dominance of copepods and especially of the estuarine species Acartia tonsa. Also, it has been hypothesized that a decrease in average taxonomic distinctness may be related to either an increase in environmental constraints which act as niche filters or to a local heterogeneity loss in terms of habitat and resource allowing the survival of only some closely related species with particular common biological attributes (Miranda et al., 2005). Conversely, high habitat heterogeneity and environmental conditions promote higher diversity levels because this enhances the coexistence of either taxonomically diverse species with contrasting ecological requirements or ecologically similar, congeneric species being either adapted to slightly different niches or able to avoid direct competition (Miranda et al., 2005).

\section{Conclusions}

In summary, variation in the hydrology pattern in the Mondego estuary induced changes in salinity and temperature, affecting zooplankton dynamics. Dry years resulted in an increase in zooplankton density, especially for Acartia tonsa and Acartia clausi and were characterised by a lack of seasonality and a higher abundance and prevalence of marine species along the year. Salinity differences, particularly in the drought year 2005, also affected spatial distribution of zooplankton species, decreasing differences between upstream and downstream communities. Despite all these changes in community structure, drought periods seem not to have affected diversity to a large extent, except for a decrease in taxonomic diversity in the initial phase. Understanding how hydrological shifts affect communities can reveal the importance of the ecological role played by climate change events on the structure of zooplankton communities (Marques et al., 2007a), demonstrating the importance of this type of studies.

\section{Acknowledgments}

The present work was supported by I.I.I. (Instituto de Investigação Interdisciplinar) through a $\mathrm{PhD}$ grant awarded to SC Marques (III/AMB/28/2005). A special thanks to all colleagues who helped during field work.

\section{References}

Atienza, D., Calbet, A., Saiz, E., Lopes, R.M., 2007. Ecological success of the cladoceran Penilia avirostris in the marine environment: feeding performance, gross growth efficiencies and life history. Marine Biology 151, 1385-1396.

Azeiteiro, U.M., Marques, J.C., Ré, P., 1999. Zooplankton annual cycle in the Mondego river estuary (Portugal). Arquivos do Museu Bocage 3, 239-263. 
Azeiteiro, U.M., Marques, J.C., Ré, P., 2000. Zooplankton assemblages in a shallow seasonally tidal estuary in temperate Atlantic Ocean (Western Portugal: Mondego estuary). Arquivos do Museu Bocage 3, 357-376.

Calbet, A., Garrido, S., Saiz, E., Alcaraz, M., Duarte, C.M., 2001. Annual zooplankton succession in coastal NW Mediterranean waters: the importance of the smaller size fractions. Journal of Plankton Research 23, 319-331.

Chiba, S., Saino, T., 2003. Variation in mesozooplankton community structure in the Japan/East Sea (1991-1999) with possible influence of the ENSO scale climatic variability. Progress in Oceanography $57,317-339$.

Chinnery, F.E., Williams, J.A., 2004. The influence of temperature and salinity on Acartia (Copepoda: Calanoida) nauplii survival. Marine Biology 145, 733-738.

Clarke, K.R., Warwick, R.M., 2001. Changes in Marine Communities: An Approach to Statistical Analysis and Interpretation. Plymouth Marine Laboratory, Plymouth, 172 pp.

David, V., Sautour, B., Chardy, P., Leconte, M., 2005. Long-term changes of the zooplankton variability in a turbid environment: the Gironde estuary (France). Estuarine, Coastal and Shelf Science 64, 171-184.

Ianora, A., 1998. Copepod life history traits in subtemperate regions. Journal of Marine Systems 15, 337-349.

Isari, S., Psarra, S., Pitta, P., Mara, P., Tomprou, M.O., Ramfos, A., Somarakis, S. Tselepides, A., Koutsikopoulos, C., Fragopoulu, N., 2007. Differential patterns of mesozooplankters' distribution in relation to physical and biological variables of the northeastern Aegean Sea (eastern Mediterranean). Marine Biology 151, 1035-1050.

Johns, D.G., Edwards, M., Greve, W., SJohn, A.W.G., 2005. Increasing prevalence of the marine cladoceran Penilia avirostris (Dana, 1852) in the North Sea. Helgoland Marine Research 59, 214-218.

Katechakis, A., Stibor, H., Sommer, U., Hansen, T., 2004. Feeding selectivities and food niche separation of Acartia clausi, Penilia avirostris (Crustacea) and Doliolum denticulatum (Thaliacea) in Blanes Bay (Catalan Sea, NW Mediterranean). Journal of Plankton Research 26, 589-603.

Kimmerer, W.J., 2002. Effects of freshwater flow on abundance of estuarine organisms: physical effects or trophic linkages. Marine Ecology Progress Series 243, 39-55.

Lam-Hoai, T., Guiral, D., Rougier, C., 2006. Seasonal change of community structure and size spectra of zooplankton in the Kaw River estuary (French Guiana). Estuarine, Coastal and Shelf Science 68, 47-61.

Marques, S.C., Azeiteiro, U.M., Marques, J.C., Neto, J.M., Pardal, M.A., 2006 Zooplankton and ichthyoplankton communities in a temperate estuary: spatial and temporal patterns. Journal of Plankton Research 28, 297-312.
Marques, S.C., Azeiteiro, U.M., Martinho, F., Pardal, M.A., 2007a. Climate variability and planktonic communities: the effect of an extreme event (severe drought) in a southern European estuary. Estuarine, Coastal and Shelf Science 73 , 725-734.

Marques, S.C., Pardal, M.A., Pereira, M.J., Gonçalves, F., Marques, J.C., Azeiteiro, U.M., 2007b. Zooplankton distribution and dynamics in a temperate shallow estuary. Hydrobiologia 587, 213-223.

Mercado, J.M., Cortés, D., García, A., Ramírez, T., 2007. Seasonal and inter-annual changes in the planktonic communities of the northwest Alboran Sea (Mediterranean Sea). Progress in Oceanography 74, 273-293.

Miranda, J.R., Mouillot, D., Hernandez, D.F., Lopez, A.S., Do Chi, T., Perez, L.A., 2005. Changes in four complementary facets of fish diversity in a tropical coastal lagoon after 18 years: a functional interpretation. Marine Ecology Progress Series 304, 1-13.

Molinero, J.C., Ibanez, F., Nival, P., Buecher, I., Souissi, S., 2005. North Atlantic climate and north-western Mediterranean plankton variability. Limnology and Oceanography 50, 1213-1220.

Ramfos, A., Isari, S., Somarakis, S., Georgopoulos, D., Koutsikopoulos, C., Fragopoulu, N., 2006. Mesozooplankton community structure in offshore and coastal waters of the Ionian Sea (eastern Mediterranean) during mixed and stratified conditions. Marine Biology 150, 29-44.

Rose, K., Roff, J.C., Hopcroft, R.R., 2004. Production of Penilia avirostris in Kingston Harbour, Jamaica. Journal of Plankton Research 26, 1-11.

Sullivan, B.K., Costello, J.H., Van Keuren, D., 2007. Seasonality of the copepods Acartia hudsonica and Acartia tonsa in Narragansett Bay, RI, USA during a period of climate change. Estuarine, Coastal and Shelf Science 73, 259-267.

Tackx, M.L.M., Nathalie, D.P., Riet, V.M., Azémar, F., Hannouti, A., van Damme, S., Fiers, F., Daro, N., Meire, P., 2004. Zooplankton in the Schelde estuary, Belgium and the Netherlands spatial and temporal pattern. Journal of Plankton Research $26,133-141$.

Taylor, A.H., Allen, J.I., Clark, P.A., 2002. Extraction of a weak climatic signal by an ecosystem. Nature 416, 629-632.

Valdés, L., López-Urrutia, A., Cabal, J., Alvarez-Ossorio, M., Bode, A., Miranda, A., Cabanas, M., Huskin, I., Anadón, R., Alvarez-Marqués, F., Llope, M., Rodríguez, N., 2007. A decade of sampling in the Bay of Biscay: what are the zooplankton time series telling us? Progress in Oceanography 74, 98-114.

Vieira, L., Azeiteiro, U.M., Ré, P., Pastorinho, R., Marques, J.C., Morgado, F., 2003. Zooplankton distribution in a temperate estuary (Mondego estuary southern arm: Western Portugal). Acta Oecologica 24S, S163-S173. 